Int. J. Electrochem. Sci., 14 (2019) 3871 - 3884

International Journal of

ELECTROCHEMICAL

SCIENCE

www.electrochemsci.org

\title{
Fabrication of Multi-parameter Chemical Sensor and its Application in the Longqi Hydrothermal Field, Southwest Indian Ocean
}

Rongrong $\mathrm{Wu}^{1,2,3}$, Chunhui Tao ${ }^{1,2,3^{*}}$, Xuegang Chen ${ }^{1}$, Ying Ye ${ }^{1}$, Xihe Yue ${ }^{2,3,5}$, Yuqiang Huang ${ }^{2,3,4}$, Yifan Zhou ${ }^{1}$, Qiuqin Wang ${ }^{1}$

${ }^{1}$ Ocean College, Zhejiang University, Zhoushan 316021, China

${ }^{2}$ Key Laboratory of Submarine Geosciences, State Oceanic Administration, Hangzhou 310012, China

${ }^{3}$ Second Institute of Oceanography, Ministry of Natural Resources, Hangzhou 310012, China

${ }^{4}$ State Key Laboratory of Geological Processes and Mineral Resources, China University of

Geoscience, Wuhan 430074, China

${ }^{5}$ College of Marine Science and Technology, China University of Geoscience, Wuhan 430074, China

*E-mail: taochunhuimail@163.com

doi: $10.20964 / 2019.03 .66$

Received: 12 October 2018 / Accepted: 12 December 2018 / Published: 7 February 2019

\begin{abstract}
All-solid-state electrodes are potentially suitable as in situ sensors for deep-sea environments because of their pressure resistance, rapid response, and ease of integration. Nonetheless, few studies report the application of such electrodes in hydrothermal systems. In this study, we fabricated a multi-parameter chemical sensor (MPCS) incorporating self-made reference, $\mathrm{pH}$, redox (Eh), and $\mathrm{H}_{2} \mathrm{~S}$ electrodes. During the Chinese Dayang 34I and 49II cruises at the Southwest Indian Ridge (SWIR), the assembled MPCS, equipped with a deep-sea towed camera system, was continuously monitored in situ at depths exceeding 2,000 $\mathrm{m}$. The potential anomalies of the $\mathrm{Eh}, \mathrm{H}_{2} \mathrm{~S}$, and $\mathrm{pH}$ electrodes were 49,98 , and $18 \mathrm{mV}$, respectively, in the Longqi hydrothermal plume area. In the undetected area, the MPCS showed slight anomalies, indicating the presence of an unknown hydrothermal plume at the site. All potential anomalies of the MPCS were consistent with those of commercial sensors (methane, turbidity, and temperature sensors). The test results suggested that the MPCS can sensitively detect changes in chemical quantities caused by hydrothermal fluid, and it provides an effective technique for exploring hydrothermal vents.
\end{abstract}

Keywords: Chemical sensor, All-solid-state selective ion electrode, Hydrothermal plume, Anomalies, Southwest Indian Ridge

FULL TEXT 
(C) 2019 The Authors. Published by ESG (www.electrochemsci.org). This article is an open access article distributed under the terms and conditions of the Creative Commons Attribution license (http://creativecommons.org/licenses/by/4.0/). 